J. Dairy Sci. 104:8338-8338

https://doi.org/10.3168/jds.2021-104-7-8338

() 2021 American Dairy Science Association ${ }^{\circledR}$. Published by Elsevier Inc. and Fass Inc. All rights reserved.

\title{
Corrigendum to "Genomic analyses and biological validation of candidate genes for rectal temperature as an indicator of heat stress in Holstein cattle" (J. Dairy Sci. 104:4441-4451)
}

\author{
Hanpeng Luo, Xiang Li, Lirong Hu, Wei Xu, Qin Chu, Aoxing Liu, Gang Guo, Lin Liu, Luiz F. Brito, \\ and Yachun Wang
}

The authors inadvertently omitted funding information for this study. The following text should be included in the Acknowledgments section:

This work was supported by a grant from the China Agriculture Research System (CARS-36), Program for Changjiang Scholar and Innovation Research Team in University (IRT_15R62), National Agricultural Genetic Improvement Program (2130135), Beijing Sciences and Technology Program (D171100002417001), and Ningxia Agricultural Breeding Program (Dairy 2019NYYZ05).

The authors regret the error.

\section{REFERENCES}

Luo, H., X. Li, L. Hu, W. Xu, Q. Chu, A. Liu, G. Guo, L. Liu, L. F. Brito, and Y. Wang. 2021. Genomic analyses and biological validation of candidate genes for rectal temperature as an indicator of heat stress in Holstein cattle. J. Dairy Sci. 104:4441-4451. https://doi.org/10 .3168/jds.2020-18725. 